\title{
Effects of the Antiarrhythmic Drug Dofetilide on Myocardial Electrical Activity: A Computer Modelling Study
}

\author{
J Saiz, JM Ferrero (Jr), M Monserrat, J Gomis-Tena, J Chorro, A Ferrero \\ Centre for Research and Innovation on Bioengineering, Valencia, Spain
}

\begin{abstract}
Dofetilide selectively inhibits the rapid component of the delayed potassium current $\left(I_{K r}\right)$. In this work, a mathematical model of dofetilide effects on $I_{K r}$ has been developed. This model has been incorporated to the Luo and Rudy (II) model of guinea pig ventricular action potential and the effect of different dofetilide concentrations on the action potential characteristics has been studied. Our results show that the steady-state block of $I_{K r}$ is dose-dependent with a block of 10\%, 53\% and 92\% for $1 \mathrm{nM}, 10 \mathrm{nM}$ and $100 \mathrm{nM}$ of dofetilide respectively $\left(I C_{50}=8.7 \mathrm{nM}\right)$. This increment of $I_{K r}$ block when the concentration increases induces a prolongation of APD also in a dose-dependent way. We observed prolongations of $A P D_{90}$ of $13 \%$ and $28 \%$ for $10 \mathrm{nM}$ and $100 n M$ of dofetilide respectively. In agreement with experimental results, the interaction between dofetilide and the receptor in the channel presents slow kinetics and reverse use-dependence in our model.
\end{abstract}

\section{Introduction}

The antiarrhythmic efficacy of drugs that induce prolongation of action potential duration (APD), through the blockade of the delayed rectifier current, $\mathrm{I}_{\mathrm{K}}$, has been widely probed in reentrant arrhythmias. In different species, as guinea pig, $\mathrm{I}_{\mathrm{K}}$ consist on two components: a slowly activating component, $\mathrm{I}_{\mathrm{Ks}}$, and a rapidly activating component, $\mathrm{I}_{\mathrm{Kr}}$, sensitive to E-4031 or sotalol [1]. Dofetilide is an antiarrhythmic drug that specifically blocks the rapid component of the delayed rectifier potassium current $\mathrm{I}_{\mathrm{Kr}}$ [2-4]. In 1999, the U.S. Food and Drug Administration (FDA) approved dofetilide for the treatment of persistent atrial fibrillation and flutter. Dofetilide is classified as a pure class III antiarrhythmic agent because it produces only prolongation of action potential duration (APD), without any effect on the resting membrane potential, action potential amplitude or maximum rate of depolarization [4]. The effect of dofetilide on APD has been recorded in different myocardial tissues and species [5,6]. In all the myocardial tissues, blockade of $\mathrm{I}_{\mathrm{Kr}}$ by dofetilide induces a higher prolongation of APD, and hence, of the QT interval, as the concentration of dofetilide increases. Prolongation of APD is related with the increment of refractory period in cardiac tissue.

While the efficacy of dofetilide as antiarrhythmic drug is related to the increment in refractoriness, the prolongation of QT may trigger the polymorphic ventricular tachycardia called torsade de pointes [7]. Different studies have found antiarrhythmic action of dofetilide in preventing and in terminating ventricular tachycardias [8] and in the prevention of atrioventriclar re-entrant tachycardia [9]. It has been also suggested that dofetilide may be useful in reducing the frequency of multiple episodes of monomorphic ventricular tachycardia and in increasing the efficacy of antitachycardia pacing in patients with implantable cardioverter-desfibrillator [10].

Dofetilide is a potent blocker of $\mathrm{I}_{\mathrm{Kr}}$. An $\mathrm{IC}_{50}$ in the nanomolar range has been experimentally measured in guinea pig ventricular myocytes, namely $8.7 \mathrm{nM}$ [11] and $31 \mathrm{nM}$ [4]; $3.9 \mathrm{nM}$ in rabbit ventricular myocytes, [3]; 11 $\mathrm{nM}$ in mouse AT-1 cells [12] and $12 \mathrm{nM}$ in HERG expressed in human cells [13]. These results are consistent with radioligand $\left(\left[{ }^{3} \mathrm{H}\right]\right.$ dofetilide) binding affinity studies that show high-affinity sites associated with $\mathrm{I}_{\mathrm{Kr}}$ with $\mathrm{IC}_{50}$ values of $28 \mathrm{nM}$ [14] and $31 \mathrm{nM}$ [15].

Experimental evidences suggest that the interaction between the drug and the receptor in the channel is produced in the open state (open channel block) rather than in the closed state $[3,13,16]$. Once the block has been produced, the effect persists during a long period at rest, suggesting that the drug does not dissociate when the channel is closed; the drug seems to be trapped within the channel $[3,16]$. It has been recently suggested that dofetilide interacts with the channels in both the open and the inactivated states [17]. The interaction between dofetilide and receptor presents a very slow kinetics $[11,13]$ and exhibits reverse use-dependence $[2,16]$. The increment in the dofetilide dose enhances the reverse-use dependence [2].

The main objective of the present work is to develop a mathematical model of the $\mathrm{I}_{\mathrm{Kr}}$ block by dofetilide and to study the effect of different concentrations on the action potential characteristics. 


\section{Methods}

In this work, the mathematical model of the cardiac action potential developed by Luo and Rudy (phase II) was used in order to simulate the guinea pig ventricular action potential. In 1995, they improved the model by replacing the $\mathrm{I}_{\mathrm{K}}$ by its two components $\mathrm{I}_{\mathrm{Ks}}$ and $\mathrm{I}_{\mathrm{Kr}}$ [18]. The formulation of the $\mathrm{I}_{\mathrm{Kr}}$ current is based on the experimental data obtained by Sanguinetti and Jurkiewicz [1]. They proposed $\mathrm{I}_{\mathrm{Kr}}$ channels with three possible states: Closed (C), Open (O) and Inactivated (I).

$$
\mathrm{C} \rightleftarrows \mathrm{O} \rightleftarrows \mathrm{I}
$$

The formulation of $\mathrm{I}_{\mathrm{Kr}}$ in de model [18] is expressed as

$$
I_{K r}=G_{K r \max } X_{r} R\left(V-E_{K r}\right)
$$

where $\mathrm{V}$ is the membrane potential, $\mathrm{E}_{\mathrm{Kr}}$ is the reversal potential, $G_{\text {Krmax }}$ is the maximum conductance of $I_{K r}, X_{r}$ is the activation gate and $\mathrm{R}$ is the time-independent inactivation gate. For a detailed description of the current see reference [18].

The blocking activity of dofetilide was simulated using the "guarded receptor hypothesis" [19], and its effect on the current was represented by introducing the factor $(1-b)$ in the $I_{K r}$ formulation (where $b$ is the fraction of channels blocked by the drug). This model of drug action assumes a drug binding to a constant affinity channel receptor guarded by the gating mechanism of the channel, unaltered by the drug. Thus, the new formulation of $\mathrm{I}_{\mathrm{Kr}}$ taking into account the effect of dofetilide is

$$
I_{K r b}=(1-b) G_{K r \max } X_{r} R\left(V-E_{K r}\right)
$$

Both the $\mathrm{I}_{\mathrm{Kr}}$ model and the cellular model (incluing the new $\mathrm{I}_{\mathrm{Krb}}$ formulation) was written in ACSL language, using Gear stiff algorithm to solve the nonlinear system of differential equations.

\section{Results and discussion}

In accordance with experimental studies that have shown drug-receptor interaction in open and in inactivated states, but not in closed states, and that the drug is trapped when the channel closes. We suggest the following model of blocking $\mathrm{I}_{\mathrm{Kr}}$ by dofetilide

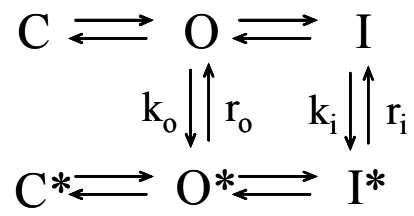

where $(*)$ indicates the drug-channel binding states, $\mathrm{k}_{\mathrm{o}}$ and $\mathrm{k}_{\mathrm{i}}$ are the association rate constants, and $\mathrm{r}_{\mathrm{o}}$ and $\mathrm{r}_{\mathrm{i}}$ are the dissociation rate constants (with open and inactivated states respectively). We consider that the forward coefficients are equal for the open and inactivated states and that the reverse coefficients are also equal. Then,

$$
k_{o}=k_{i}=k \text { and } r_{o}=r_{i}=r
$$

From this model, the blocking factor $b$ can be calculated as

$$
\frac{d b}{d t}=\left\{X_{r} R+(1-R)\right\}\{k[D](1-b)-r b\}
$$

We used the dissociation constant $r=0.0036 \mathrm{~s}^{-1}$, obtained by Duff et al [14], using radioligand $\left(\left[{ }^{3} \mathrm{H}\right]\right.$ dofetilide) binding affinity studies, for the high-affinity sites identified in guinea pigs ventricular myocytes. From the value $\mathrm{IC}_{50}$ of $8.7 \mathrm{nM}$ recorded by Weerapura et al [11], we estimated the association rate constant $\mathrm{k}$, $\left(\mathrm{IC}_{50}=\mathrm{r} / \mathrm{k}\right)$, as $\mathrm{k}=0.4137 \mu \mathrm{M}^{-1} \mathrm{~s}^{-1}$.

These values are similar to those obtained in different experimental conditions as: $\mathrm{k}=0.6 \mu \mathrm{M}^{-1} \mathrm{~s}^{-1}$ [13] and $\mathrm{k}=$ $0.1 \mu \mathrm{M}^{-1} \mathrm{~s}^{-1}$ and $\mathrm{r}=0.003 \mathrm{~s}^{-1}[15]$

In order to test the dofetilide-channel binding model, we applied voltage-clamp protocols of stimulation to the $\mathrm{I}_{\mathrm{Krb}}$ model.

In Figure 1, the evolution of the normalized current $\left(\mathrm{I}_{\mathrm{Krb}} / \mathrm{I}_{\mathrm{Kr}}\right)$ when a voltage clamp protocol (from $-40 \mathrm{mV}$ to $0 \mathrm{mV}$ ) was applied to the $\mathrm{I}_{\mathrm{Krb}}$ model for a dofetilide concentration of $50 \mathrm{nM}$ is shown. The symbols represent the experimental results obtained by Weerapura et al [11] and the solid line shows the results of the $\mathrm{I}_{\mathrm{Krb}}$ model. The model indicates that the $\mathrm{I}_{\mathrm{Krb}}$ decays with a time constant of $41 \mathrm{~s}$ very close to that recorded experimentally (36.6 s)

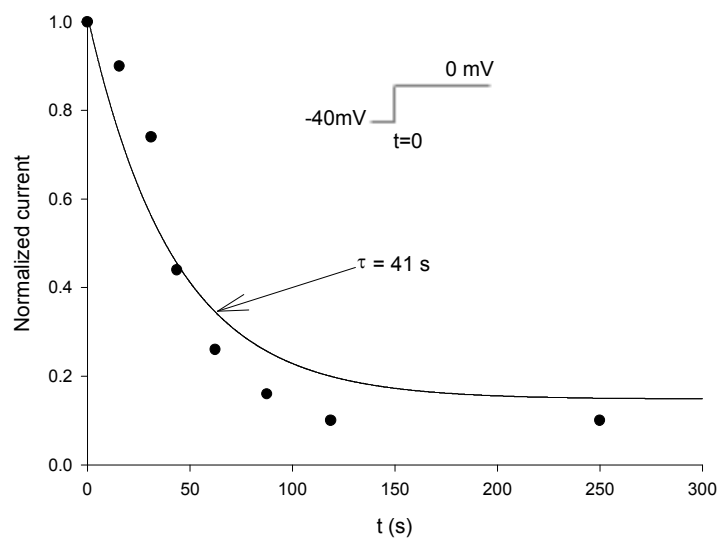

Figure 1. Voltage clamp protocol (indicated in the figure) was used to compare the experimental results obtained when dofetilide $50 \mathrm{nM}$ is applied to ventricular guinea pig cells. Symbols correspond to experimental results, the line is the evolution indicated by the $\mathrm{I}_{\mathrm{Krb}}$ model 
In Figure 2, the same voltage clamp protocol was applied, this time from $-80 \mathrm{mV}$ to $+10 \mathrm{mV}$, for different concentrations of dofetilide ([D]), in the range from $1 \mathrm{nM}$ to $1 \mu \mathrm{M}$. It is possible to observe that the block is faster when the dofetilide concentration increases. For this voltage-clamp protocol, the time constant for a $[\mathrm{D}]=300$ $\mathrm{nM}$ resulted from the model is $7.5 \mathrm{~s}$ (plot not shown), closed to recorded experimentally $(5.2 \mathrm{~s})$ by Snyders et al [15].

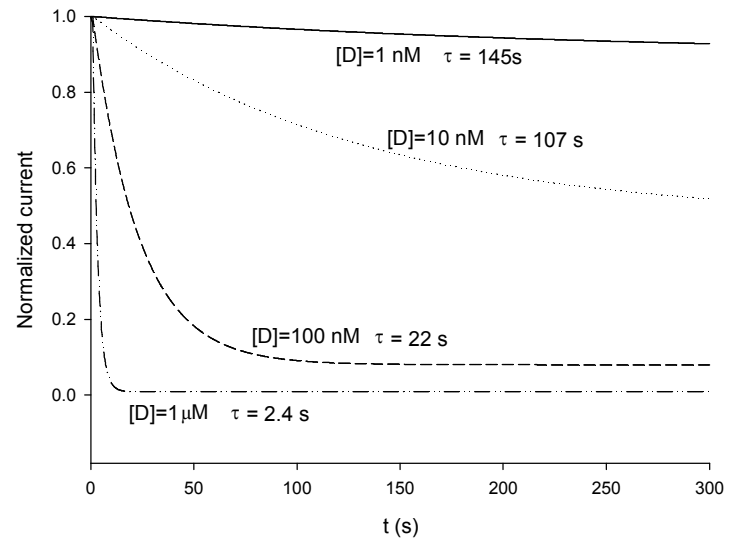

Figure 2. Time course of blocking (from the $\mathrm{I}_{\mathrm{Krb}}$ model) for different concentrations of dofetilide, when a voltage clamp protocol (indicated in the figure 1, but from $-80 \mathrm{mV}$ to $+10 \mathrm{mV}$ ) is used.

In Figure 3, the steady-state blockage effect of different concentrations of dofetilide on the $\mathrm{I}_{\mathrm{Kr}}$ (a) and on the action potential (b) are shown. For all the simulations, the cellular model was stimulated, until the steady-state was reached, with a rectangular current pulse with an amplitude 1.5 times the diastolic threshold and a duration of $2 \mathrm{~ms}$. Only the magnitudes associated to the last stimulation pulse are shown. From the figure, it is observed that as the concentration of dofetilide is increased from $1 \mathrm{nM}$ to $1 \mu \mathrm{M}$, the maximum value (peak) of $\mathrm{I}_{\mathrm{Kr}}$ decreased from $\mathrm{APD}_{90} 10 \%$ to $99 \%$, and, as a consequence of the $\mathrm{I}_{\mathrm{Kr}}$ block, the $\mathrm{APD}_{90}$ increases from $2 \%$ to $29 \%$. The theoretical values obtained using the model are in agreement with the experimentally recorded ones. Yang et al [20] obtained an increment of $26 \%$ of $\mathrm{APD}_{90}$, when guinea pig papillary muscles were treated with dofetilide (100 nM). Similar values have been obtained experimentally in other species. Baskin et al [5] recorded an increment of isolated ferret ventricular ERP of approximately 10-20\% for different values of dofetilide concentration (10 nM-10 $\mu \mathrm{M})$. Recently, Hua et al [6] observed that dofetilide $(10 \mathrm{nM})$ increased $\mathrm{APD}_{90}$ at $1 \mathrm{~Hz}$ by $24 \%$, in isolated guinea pig Purkinje fibers. The higher blocking effect observed in Purkinje fibers is due to the fact that dofetilide is more potent in Purkinje fiber than in ventricular muscle.
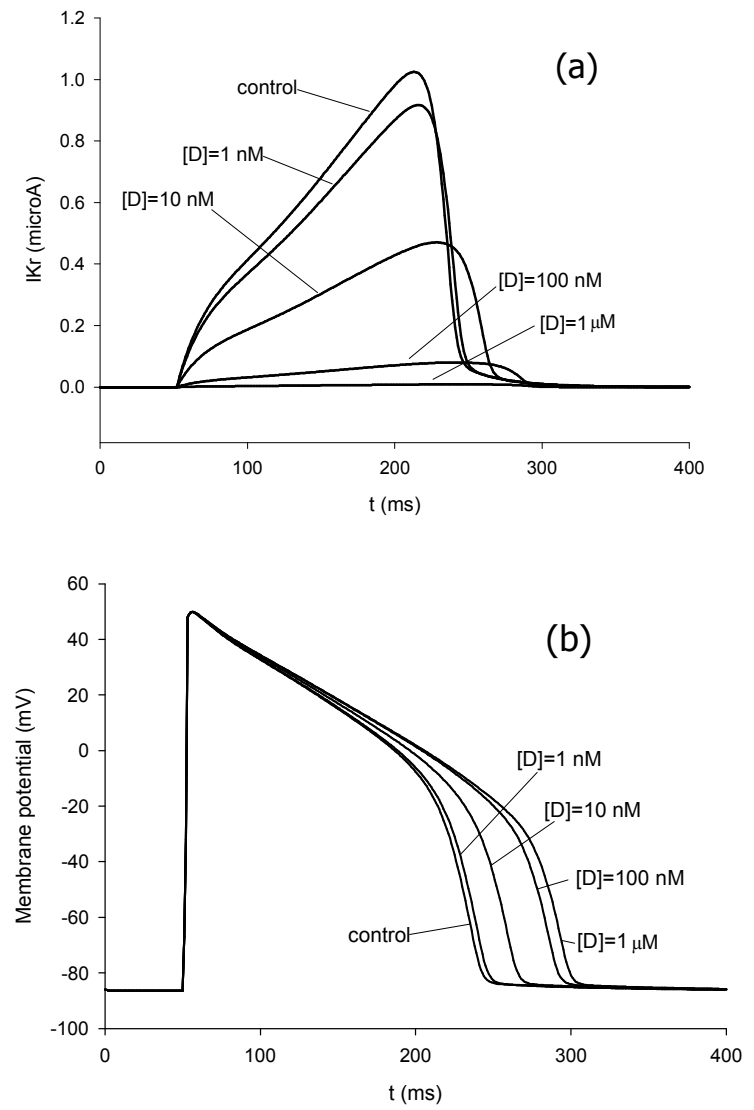

Figure 3. Effect of dofetilide concentration on $\mathrm{I}_{\mathrm{Kr}}$ (a) and on the action potential (b) obtained with the model.

The model proposed reproduces the reverse usedependence effect of dofetilide. Due to this effect, the prolongation of action potential duration increases when the stimulation frequency is reduced. In Figure 4 it is possible to observe the increment in $\mathrm{APD}_{90}$ induced by different concentrations of dofetilide at different pacing cycle length.

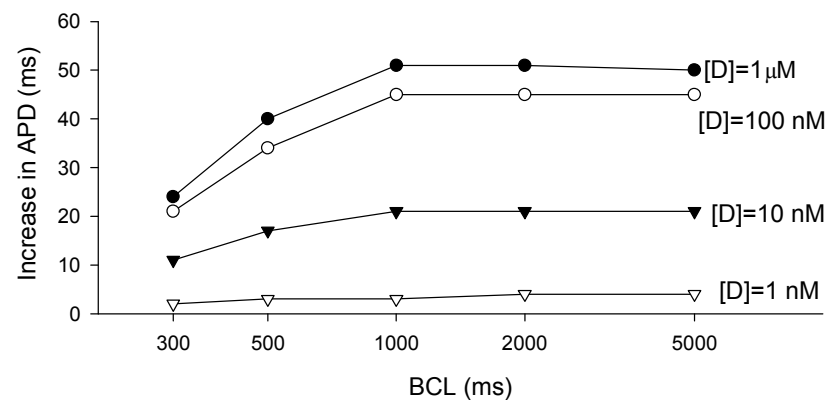

Figure 4. Increment in $\mathrm{APD}_{90}$ induced by different dofetilide concentrations at different basic cycle length (BCL) 
From the results shown in the figure, it is possible to observe that the dofetilide presents reverse usedependence in all range of concentration tested ( $1 \mathrm{nM}$ to $1 \mu \mathrm{M})$. Even more, when the concentration of dofetilide increases, the reserve use-dependent is enhanced. However, for BCL higher than $1000 \mathrm{~ms}$ the increment of APD90 does not change significantly with the BCL. This behaviour is very similar to the observed experimentally [2], see Figure 3 in reference [16].

\section{Conclusions}

A model of the dofetilide- $\mathrm{I}_{\mathrm{Kr}}$ binding has been presented. The model is based on experimental results and takes into account the recent experimental evidence that suggest an interaction between dofetilide and the membrane receptor when the channels are in both, open and inactivated state, and that indicate that the drug is trapped when the channel is in closed state. The block kinetics and the increment of $\mathrm{APD}_{90}$ for different concentrations of dofetilide are in good agreement with experimental results. The model also reproduces the reverse use dependence behaviour observed in this drug.

\section{Acknowledgements}

This work is partially supported by the Plan Nacional de Investigación Científica, Desarrollo e Innovación Tecnológica del Ministerio de Ciencia y Tecnología of Spain (TIC 2001-2686)

\section{References}

[1] Sanguinetti MC, Jurkiewicz NK. Two components of cardiac delayed rectifier K current. Differential sensitivity to block by class III antiarrhythmic agents. J Gen Physiol 1990;96:195-215.

[2] Tande PM, Bjornstad H, Yang T, Refsum H. Ratedependent class III antiarrhythmic action, negative chronotropy, and positive inotropy of the novel blocking drug, UK-68,798: Potent in guinea pig but no effect in rat myocardium. J Cardiovasc Phamacol 1990;16:401-410.

[3] Carmeliet E. Voltage and time-dependent block of the delayed $\mathrm{K}$ current in cardiac myocytes by dofetilide. $\mathrm{J}$ Pharmacol Exp Ther 1992;262:809-817.

[4] Jurkiewicz NK, Sanguinetti MC. Rate-dependent prolongation of cardiac action potentials by a methanesulfonanilide class III antiarrhythmic agent. Cir Res 1993;72:75-83.

[5] Baskin EP, Lych JJ(Jr). Differential atrial versus ventricular activities of class III potassium channel blockers. J Pharmacol Exp Ther 1998;285:135-142.

[6] Lu HR, Marien R, Saels A, Clerck F. Species plays an impostant role in drug-induced prolongation of action potential duration and early afterdepolarizations in isolated purkinje fibers. J Cardiovasc Electrophysiol 2001;12:93102.

[7] Barret TD, Hennan JK, Fischbach PS, O'neill BP, Discroll EM (Jr), Luchesi BR. BR J Pharmacol 2001;132:14931500.

[8] Bashir Y, Thomsen PB, Kingma JH, Moller M, Wong C,
Cobbe SM, Jordaens L, Campbell RWF, Rasmussen HS, Camm J. Electrophysiologic profile and efficacy of intravenous dofetilide (UK-68,798), a new class III antiarrhythmic drug, in patients with sustained monomorphic ventricular tachycardia. Am J Cardiol 1995;76:1040-1044.

[9] Cobbe SM, Campbell RWF, Camm AJ, Nathan AW, Rowland E, Bloch-Thomsen PE, Moller M, Jordains L. Effects of intravenous dofetilide on induction of atrioventricular re-entrant tachycardia. Heart 2001;86:522526.

[10] Mazur A, Anderson ME, Bonney S, Roden DM. Pausedependent polymorphic ventricular tachycardia during long-term treatment with dofetilide. J Am Coll Cardiol 2001;37:1100-1105.

[11] Weerapura M, Nattel S, Chartier D, Caballero R, Hebert TE. A comparison of currents carried by HERG, with and without coexpression of MiRP1, and the native rapid delayed rectifier currents. Is MiRP1 the missing link? Journal of Physilogy 2002a;540:15-27.

[12] Yang T, Snyders J, Roden DM. Rapid inactivation determines the rectification and $[\mathrm{K}]_{\mathrm{o}}$ dependence of the rapid component of the delayed rectifier $\mathrm{K}$ current in cardiac cells. Cir Res 1997;80:782-789.

[13] Snyders DJ, Chaudhary A. High affinity open channel block by dofetilide of HERG expressed in human cell line. Mol Pharmacol 1996;49:949-955.

[14] Duff HJ, Feng Z, Sheldon RS. High- and low- affinity sites for $\left[{ }^{3} \mathrm{H}\right]$ dofetilide binding to guinea pig myocytes. Circ Res 1995;77:718-725.

[15] Fiset C, Feng Z, Wang L, Sheldon RS, Duff HJ. $\left[{ }^{3} \mathrm{H}\right]$ dofetilide binding: biological models that manifest solely the high or the low affinity binding site. J Moll Cell Cardiol 1996;28:1085-1096.

[16] Ohler A, Amos GJ, Wettwer E, Ravens U. Frequencydependent effects of E-4031,almokalant, dofetilide and tedisamil on action potencial duration: no evidence for "reverse use dependent" block. Naunyn-Schmiedeberg's Arch Pharmacol 1994;349:602-610.

[17] Weerapura M, Hebert TE, Nattel S. Dofetilide block involves interactions with open and inactivated states of HERG channels. Eur J Physiol 2002;443:520-531.

[18]Zeng J, Laurita KR, Rosenbaum DS, Rudy Y. Two components of the delayed rectifier $\mathrm{K}$ current in ventricular myocytes of the guinea pig type. Circ Res1995;77:140-152.

[19] Grant AO, Starmer CF, Strauss HC. Antiarrhythmic drug action. Blockade of the inward sodium current. Circ Res 1984;55(4):565-576.

[20] Yang T, Tande PM, Lathorp DA, Refsum H. Class III antiarrhythmic action by potassium channel blockade: dofetilide attenuates hypoxia induced electromechanical changes. Cardiovas Res 1992; 26:1109-1115.

Address for correspondence.

Javier Saiz.

Centro de Investigación e Innovación en Bioingeniería

Universidad Politécnica de Valencia

Camino de Vera s/n

46071 Valencia

Spain

E-mail: jsaiz@eln.upv.es 